\title{
Identification of the proto-inkstone by organic residue analysis: a case study from the Changle Cemetery in China
}

\author{
Meng Ren ${ }^{1,2}$, Renfang Wang ${ }^{3}$ and Yimin Yang ${ }^{2^{*}}$
}

\begin{abstract}
The inkstone is a specific writing implement in China that was popularized since the Han Dynasty (202 BC-AD 220). A rectangular/round grinding plate accompanied with a grinding stone is considered as a kind of proto-inkstone. However, little scientific investigation has been performed to support this hypothesis. In this paper, a micro-destructive approach, including Fourier transform infrared spectroscopy (FTIR), Raman spectroscopy and gas chromatography coupled with mass spectrometry (GC-MS), were employed to analyse the black residues on a grinding plate and a grinding stone excavated from the Changle Cemetery (202 BC-AD 8) in northwestern China. The FTIR and Raman analyses indicated that the residues were ancient ink. GC-MS analysis further identified that the residues were pinesoot ink, based on the relative abundances of the main polycyclic aromatic hydrocarbons, as well as the detection of conifer biomarkers. The trace of animal glue was not detected in the residues; thus, the ink was possibly formed as small pellets and the small grinding stone was necessary to assist during the ink-grinding process. This study confirms that this set of stone implements is indeed an early type of inkstone, and offers some insight into the co-evolution relationship between ink production and inkstone shapes.
\end{abstract}

Keywords: Chinese inkstone, Shape, Pine-soot ink, Dehydroabietic acid

\section{Introduction}

The inkstone is used to grind solid ink products with water into liquid ink, which is necessary in Chinese calligraphy and brush painting [1]. The inkstick, ink brush, paper and inkstone are called Four Treasures of the Study and have important cultural values in Chinese history. The inkstone developed from primitive grinding tools since approximately 6000-7000 years ago [2]. A set of stone artefacts, including a grinding plate and a grinding stone, were found in a tomb in Yunmeng County, Hubei Province, dated back to the third century BC, and is regarded as the earliest excavated inkstone due to the associated ink pellets [3]. Ink and inkstone were gradually popularized during the Western Han Dynasty (202 $\mathrm{BC}-\mathrm{AD} 8$ ) with the development of the social economy

\footnotetext{
*Correspondence: yiminyang@ucas.ac.cn

2 Department of Archaeology and Anthropology, University of Chinese

Academy of Sciences, Beijing 100049, People's Republic of China

Full list of author information is available at the end of the article
}

and culture. There are two important types of Chinese artificial ink, pine-soot ink and oil-soot ink, mainly made from the soot of burnt pine woods and oils respectively $[4,5]$. According to historical records, the production of pine-soot ink sprouted in the Qin Dynasty (221-207 BC), matured in the East Han Dynasty (AD 25-220), greatly improved in Wei-Jin period (AD 220-420) and then peaked in the Tang and Song Dynasties (AD 618-1279). Following this, the oil-soot ink surpassed pine-soot ink [5]. However, the manufacturing technology in the early stage is not clear due to the lack of scientific analysis.

The shape of inkstones has varied and changed over time. Additional file 1: Figure S1 shows the development of inkstones since the Western Han Dynasty. A round or rectangular stone plate accompanied with a small grinding stone has been supposed to be in the early development stage of inkstones, which we call as the proto-inkstone. This inkstone was designed in this way, because the contemporary inks were mainly formed in small pellets, which could not be ground directly against 
an inkstone without the help of another smaller grinding stone $[5,6]$. These grinding plates with a grinding stone are often found in the Han tombs, as hypothetical proto-inkstones. The current studies on these inkstones are restricted to their forms, textures, classifications and manufacture skills, but their functions are mainly interpreted in terms of their morphology, as well as the characteristics of the associated funeral objects [7, 8]. However, the morphological method is inadequate to determine the usage of these stone artefacts, and sometimes they have also been thought as grain-processing tools $[9,10]$. In addition, there are various names for these proto-inkstones in different excavation reports, such as "grinding slab", "grinding plate", "inkslab", "flat inkstone", and sometimes even simply "grinding tools". Visible residues were occasionally found on these inkstones, which would provide direct chemical evidence to support their functional interpretation; however, relevant organic residue analysis has never been reported up to our knowledge.

Some scholars further consider that the prevalence of small ink pellets before the Eastern Han Dynasty probably resulted from the lack of animal glue in ink making process, because glue is the essential component to help holding soot particles together in a large solid form $[5,11]$. The ink manufacturing technology had been improved during the Eastern Han Dynasty, and the shape of ink had gradually developed into the large ingot-type, which can be ground directly against an inkstone. Then the small grinding stone was no longer needed [6], and the mature concave inkstone appeared in the Wei-Jin period $[7,8]$. Therefore, it has been assumed that the development of the inkstick promoted that of the inkstone [11]. However, few studies have compared the chemical difference between ink pellets and inksticks to confirm this explanation. On the other hand, several attempts have been made to examine the chemical and physical properties of Chinese ink: Swider et al. [12]. adopted Photon Correlation Spectroscopy (PCS) size measurements and scanning electron microscopy (SEM) to characterize the size and morphology of soot particles; Wei et al. [4, 13]. set up a criterion to differentiate the two main types of Chinese ink (pine-soot and oil-soot ink) using pyrolysis-gas chromatography-mass spectrometry (Py/GCMS), and then studied the ingredients of an Eastern Jin Chinese inkstick (AD 317-420). In addition, research on ink in other cultures has also been reported $[14,15]$. However, the sampling method for ancient ink is often destructive and may not be suitable in some cases.

In this paper, the black residues on a grinding plate and grinding stone unearthed in a Han tomb at the Changle Cemetery in Zhongwei (Ningxia, China) were characterised through Fourier transform infrared spectroscopy
(FTIR) and Raman spectroscopy, in order to verify whether they were writing inks, as well as indicating the presence/absence of animal glues. It is noteworthy that the black residues on the grinding stone are loose flakes; however, only a thin layer of black residue is attached to the smooth surface of the grinding plate, which is not allowed to run through the frequently-used destructive sampling protocols in order to avoid generating surface scratches. Thus, a micro-destructive sampling approach was designed and then gas chromatography coupled with mass spectrometry (GC-MS) was adopted to distinguish the type of Chinese ink, and to investigate the additives which might be added to the ink samples. These samples provide a rare opportunity to determine the composition of early ink and reveal the function of the excavated stone implements. Furthermore, the co-evolution relationship between inkstone shapes and ink manufacture would be discussed.

\section{Materials and methods \\ Materials}

The Changle Cemetery $\left(37^{\circ} 26^{\prime} 24.8^{\prime \prime} \mathrm{N}, 105^{\circ} 05^{\prime} 43.0^{\prime \prime} \mathrm{E}\right)$ is located $2.5 \mathrm{~km}$ south of Changle Town, Shapotou District in Zhongwei City, Ningxia Province (Fig. 1a). This site was firstly investigated in 1985, and then excavated in 2002, 2004 and 2009. From May to November, 2012, the field team carried out the fourth archaeological excavation in the southern area. During this excavation, 24 Han tombs and 270 pieces/sets of funeral objects were excavated and a set of stone artefacts, including a grinding stone and a plate (Fig. 1b, c), was unearthed in Tomb M15. This tomb is a medium-sized rectangular stone grave with a single occupier dated back to the mid-late Western Han Dynasty (140 BC-AD 8). Apart from the grinding plate and grinding stone, an iron sharpener, a wooden coffin, a skull of a lamb, some potteries and Wuzhu-coins were also found in this tomb. According to the structure of the tomb and the features of unearthed objects, the tomb occupier might be an official scribe [16].

Both grinding stone and grinding plate are made of dark grey sandstone, and, more importantly, there are black residues on the surfaces. The grinding stone (Fig. 1b, coded as 12SCM15:8) is a slightly rough cylinder-shaped platform with a squared base, which is convenient for grinding inks. The grinding plate (Fig. 1c, coded as 12SCM15:9) is a flat rectangle with a smooth black surface and was broken in the middle when excavated. The residues were only found on the grinding surfaces of both the grinding stone and the plate, and they were labelled as sample I and sample II, respectively. Those residues are considered to be writing ink and the stone artefacts are regarded as a set of proto-inkstone. In 


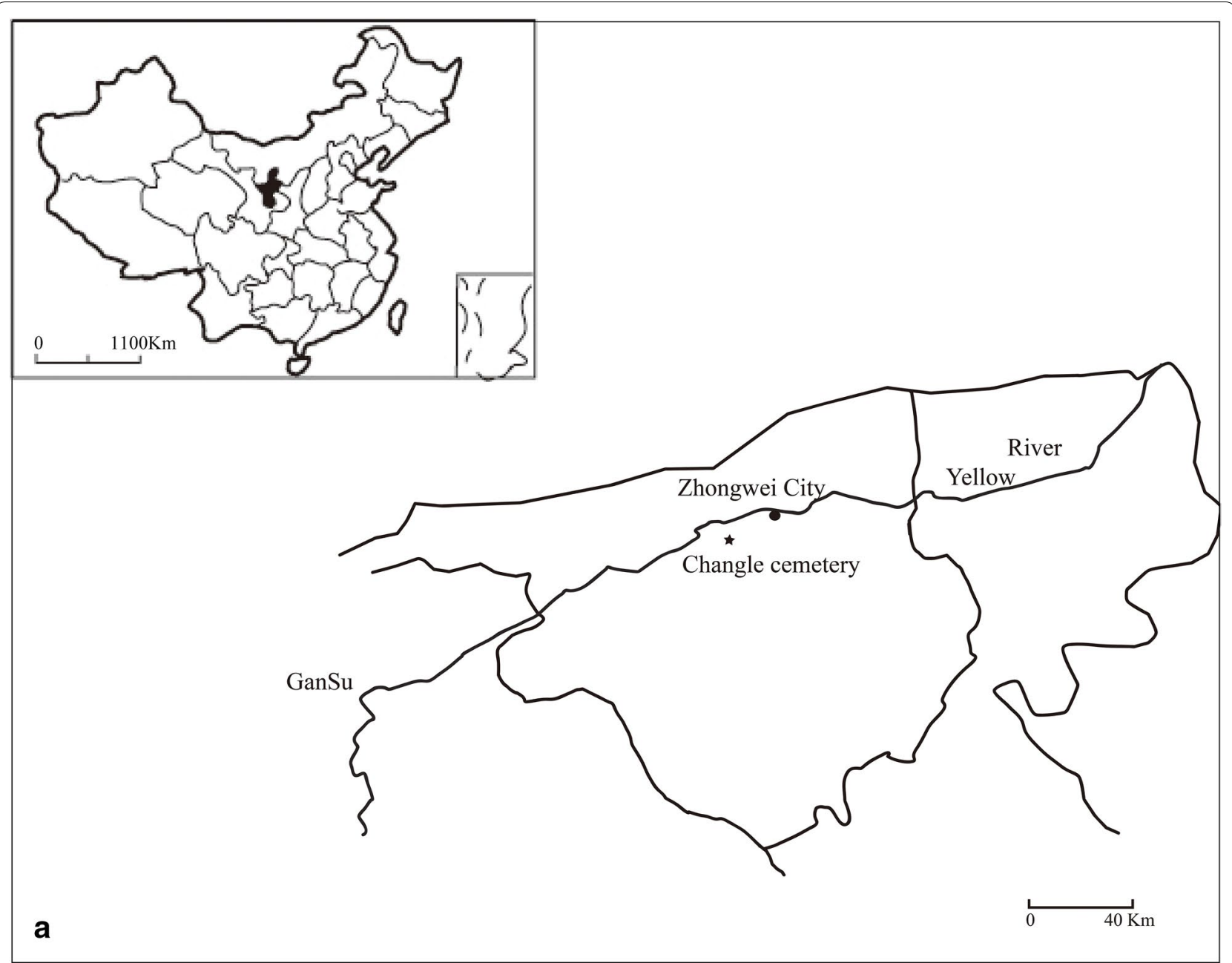

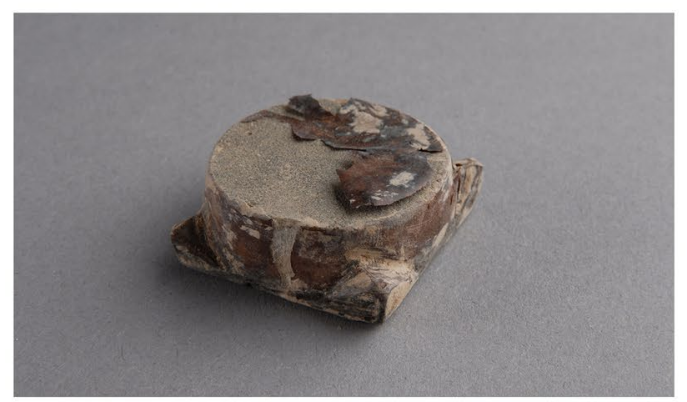

b

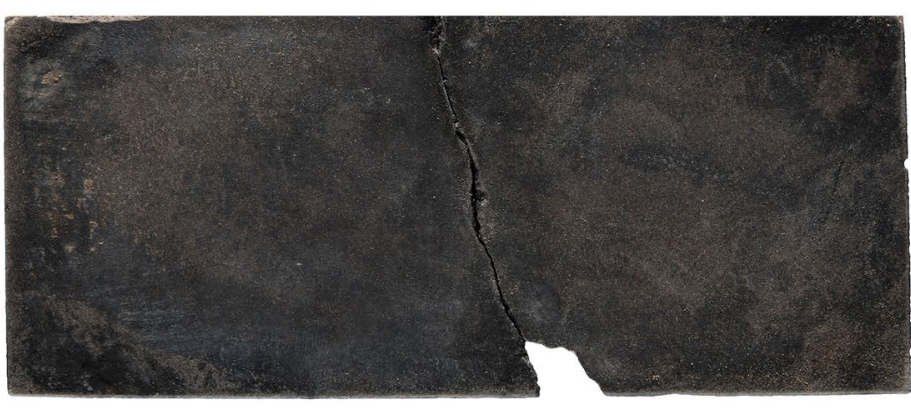

C

Fig. 1 a The location of the Ningxia province in China and the location of the Changle Cemetery in Ningxia; $\mathbf{b}$ the archaeological grinding stone (12SCM15:8) and $\mathbf{c}$ the grinding plate (12SCM15:9)

addition, the tomb M15 does not show any sign of burning, suggesting that the black residue samples were not from the burial environment.

The modern pine soot powder and a modern pine-soot inkstick are also analysed for comparison. The reference materials are all obtained from Hukaiwen Factory in China, which is a modern factory producing soot to make inksticks. The modern pine soot powder is made by burning pine wood, and sometimes stems and leaves of pine trees are also used. The modern pine-soot inkstick is 
made by the same pine soot, with the addition of animal glue and additives such as borneol (Chinese name Bing pian). In addition, replicas of modern ink samples are made by applying pine soot with water on two glass slides (labelled as PS1 and PS2).

\section{FTIR-ATR analysis}

The infrared spectra were recorded using a Nicolet 6700 (Thermo Scientific) FTIR spectrometer with the ATR measuring accessory. Micro samples were removed from the stones via gentle scrapping with a scalpel. Spectra were acquired over the range of $4000-400 \mathrm{~cm}^{-1}$ with a resolution of $4 \mathrm{~cm}^{-1}$ and 32 scans per spectrum. The software OMNIC 8.0 was used to process the data.

\section{Raman spectroscopy analysis}

The Raman spectra were acquired with a LabRAM HR 800 instrument (Jobin-Yvon-Horiba), using a $532 \mathrm{~nm}$ laser at $2 \mathrm{~cm}^{-1}$ spectral resolution. The spot analysed was focused with a $\times 50$ objective lens. The power used was about $2-3 \mathrm{~mW}$, and the recording time was $30 \mathrm{~s}$.

\section{GC-MS analysis}

Although the mixed-solvent was often used for extraction in the published studies; we found that soot particles was difficult to precipitate in mixed solvent, such as chloroform/methanol $(2: 1 \mathrm{~V} / \mathrm{V})$, during the centrifugation. After several experiments, it was found that acetone has better separation effect for soot particles, and Additional file 2: Figure $\mathrm{S} 2$ shows the extraction solvent of chloroform/methanol and acetone after centrifugation. A modern inkstick with known components was analysed to examine the extraction ability of acetone.

The loose flakes (sample I) can be easily removed from the grinding stone (12SCM15:8) by a scalpel; however, it may cause surface scratches for the grinding plate (12SCM15:9), and thus washing with solvent might be a less destructive and safe way for extracting sample II. Replicas of modern pine soot (PS1 and PS2) were analysed prior to the archaeological samples in order to evaluate the influence of the different sampling methods. Sample PS1 was collected by a scalpel from the slide, and transferred into a $5 \mathrm{~mL}$ Eppendorf tube. Then $3 \mathrm{~mL}$ of acetone was added. While sample PS2 was rinsed directly from the slide with acetone. All of the extractions were facilitated by sonication for $3 \times 20 \mathrm{~min}$. After centrifugation, the supernatant was transferred to a second Eppendorf tube and evaporated until dryness under a stream of nitrogen. The retained dry residue was then derivatized with $50 \mu \mathrm{L}$ of $\mathrm{N}, \mathrm{O}$-bis (trimethylsilyl) trifluoroacetamide (BSTFA) containing 1\% trimethylchlorosilane (TMCS) for $1 \mathrm{~h}$ at $70{ }^{\circ} \mathrm{C}$. After cooling to the room temperature, the derivatization reagent was evaporated, and the resulting trimethylsilyl derivatives were re-dissolved in $1 \mathrm{~mL}$ of hexane.

GC-MS analysis was performed with a 7890A gas chromatography coupled with a 5975C quadrupole mass spectrometer (Agilent Technologies). Chromatographic separation was performed on an HP-5MS fused silica capillary column $(30 \mathrm{~m} \times 0.25 \mathrm{~mm} \times 0.25 \mu \mathrm{m})$, which was operated using a temperature programme as follows: the initial temperature was set at $60^{\circ} \mathrm{C}$ for $2 \mathrm{~min}$ and was then increased by $10^{\circ} \mathrm{C} / \mathrm{min}$ up to $150{ }^{\circ} \mathrm{C}, 2 \mathrm{~min}$ isothermal, $3{ }^{\circ} \mathrm{C} / \mathrm{min}$ up to $290{ }^{\circ} \mathrm{C}$ and held isothermal at $290{ }^{\circ} \mathrm{C}$ for $10 \mathrm{~min}$. Helium was used as the carrier gas at a constant flow rate of $1.0 \mathrm{~mL} \mathrm{~min}^{-1}$. The injection volume was $1 \mu \mathrm{L}$, and the splitless mode was applied. The sample was ionized by electron ionization $(70 \mathrm{eV})$, the MS ion source temperature was $230{ }^{\circ} \mathrm{C}$, the interface temperature was $280{ }^{\circ} \mathrm{C}$, and the MS quadrupole temperature was $150{ }^{\circ} \mathrm{C}$. The mass spectrometer was set from $\mathrm{m} / \mathrm{z} 40$ to 600 . The selected ions for GC-SIM-MS are $\mathrm{m} / \mathrm{z} 178$ (Phenanthrene, S1), m/z 202 (Fluoranthene, S2), m/z 202 (Pyrene, S3), $\mathrm{m} / \mathrm{z} 228$ (Triphenylene and its isomer, S4), $\mathrm{m} / \mathrm{z} 252$ (Benzo[k]fluoranthene and its isomers, S5). Agilent MSD ChemStation was used to deal with the data.

The total ion current chromatograms of PS1 and PS2 showed similar results, indicating that the sampling method by rinsing have the same extraction efficiency with the destructive sampling method, and the effect of different sampling techniques can be neglected in this study. Detailed information is provided in Additional file 3: Figure S3 and Additional file 4: Figure S4. Apart from various polycyclic aromatic hydrocarbons, borneol, which is a common additive used in Chinese ink, was also detected in the modern inkstick (Additional file 5: Figure S5). The results further proved that extracting by acetone rinsing can provide the overall information about the relevant organic substances in ink samples. Therefore, the ancient residues on the grinding stone and the grinding plate were sampled by scraping and rinsing respectively, and the extracts were analysed in the same way as the modern samples. Blank sample and the back side of the grinding plate (12SCM15:9) which was sampled by rising were also analysed to check laboratory and environmental contamination.

\section{Results and discussion}

\section{The identification of ink and inkstone}

FTIR results (Fig. 2) revealed that the archaeological samples and pine soot all show the transmission band at approximately $1580 \mathrm{~cm}^{-1}$, which is assigned to aryl$\mathrm{H}$ group in aromatic six-rings, indicating that PAHs are the prominent organic components in the black residues [17]. The band around $1419 \mathrm{~cm}^{-1}$ could be attributed to the $\mathrm{C}-\mathrm{H}$ deformation of $\mathrm{CH}_{2}$ or $\mathrm{CH}_{3}$ groups or to the $\mathrm{OH}$ 


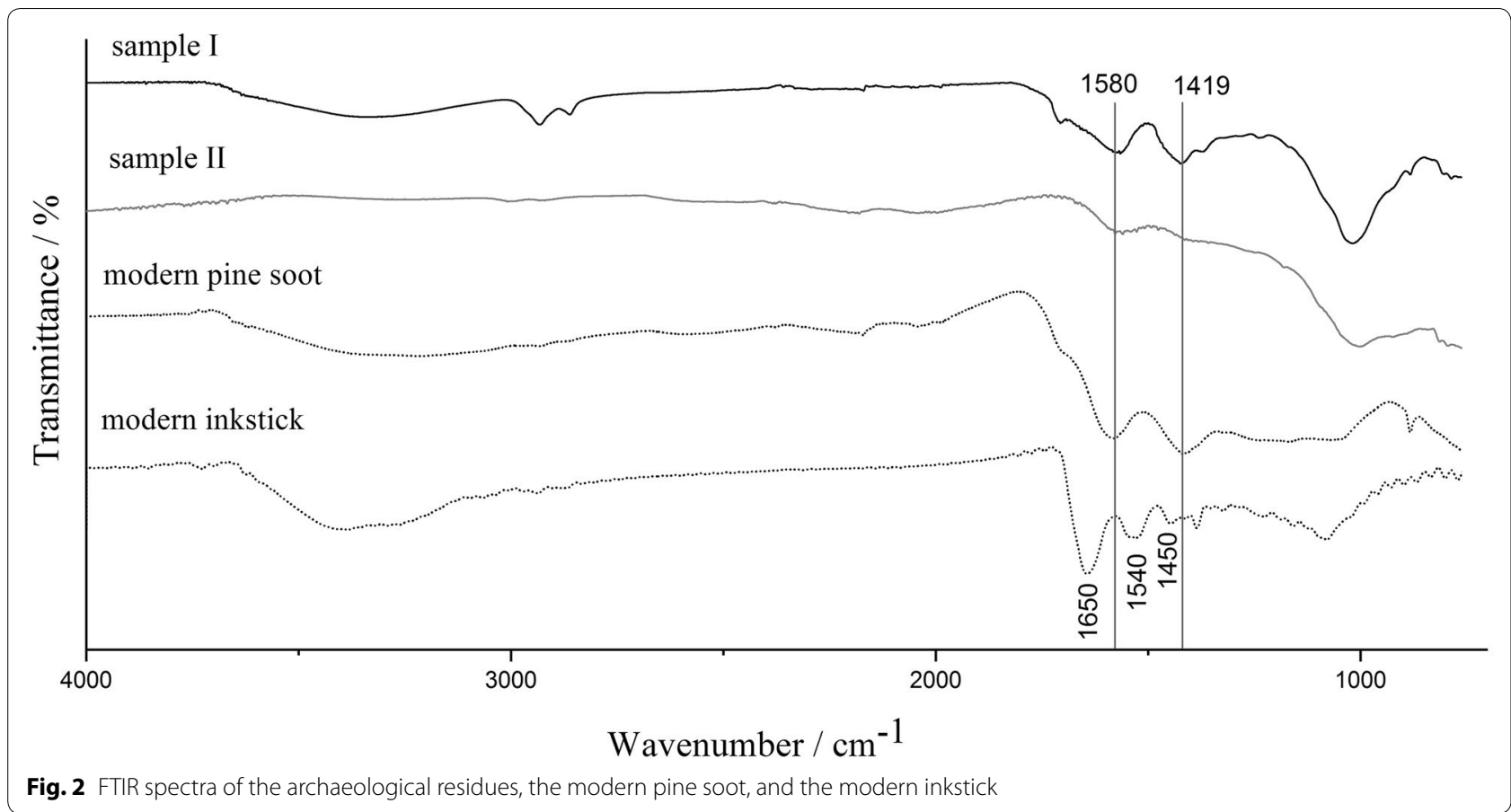

deformation and $\mathrm{C}-\mathrm{O}$ stretching of phenolic groups [18, 19]. The band near $1100-1000 \mathrm{~cm}^{-1}$ in the archaeological samples is the $\mathrm{Si}-\mathrm{O}-\mathrm{Si}$ asymmetric stretching region of silica, which may have originated from soil [17]. In addition, transmission bands around $2900 \mathrm{~cm}^{-1}$ ascribing to $\mathrm{C}-\mathrm{H}$ stretching, are commonly existed in organic materials and are not characteristic. More importantly, the modern inkstick, which is mainly made by pine soot and animal glue, shows the presence of protein with the characteristic signals of the amide group $(-\mathrm{N}(\mathrm{H})-\mathrm{C}=\mathrm{O}-)$ at 1650, 1540 and $1450 \mathrm{~cm}^{-1}$ [20]. Animal glue has been commonly used as the binding media in Chinese ink. However, the transmission bands of glue are not present in the archaeological samples and modern pine soot, suggesting that very little or no binder was used in the ink residues.

The Raman spectra of both archaeological samples and reference materials showed two peaks at around 1596 and $1360 \mathrm{~cm}^{-1}$ (Fig. 3), which are characteristic of black carbon $[21,22]$. This result also indicated that the black residues were mainly soot condensates, and further confirmed that this set of stone artefacts was a protoinkstone used for grinding ink during the Western Han Dynasty. The peak at $458 \mathrm{~cm}^{-1}$ in sample II is ascribed to silica, and the slight differences of Raman results between two ancient samples was probably due to the non-uniform surface of the stones.

As mentioned, proto-inkstones in the Western Han Dynasty were distinct from the later mature inkstones in morphology. They often consisted of two parts: a grinding plate and a small grinding stone (with ink pellets ground between them). In fact, the Chinese character for inkstone first appeared in ancient literatures shuowen and shiming written in the Eastern Han Dynasty and was never used before. The wide use of proto-inkstone in the Han Dynasty might stimulate the invention of the Chinese character for inkstone.

\section{The raw material of ink}

Based on the micro-destructive analysis procedure, the total ion current chromatograms of the archaeological residues are presented in Fig. 4 and the peak assignments and compound information are listed in Table 1. The results show that both samples contain large amounts of polycyclic aromatic hydrocarbons (PAHs), including phenanthrene, fluoranthene, pyrene, benz[a]anthracene, triphenylene, benzo[a]pyrene, benzo[k]fluoranthene, benzo[b]fluoranthene and indeno[1, 2, 3-cd]pyrene, which demonstrated that the residues were derived from combustion. In addition, $\beta$-sitosterol suggested a vegetal origin. However, the fatty acids detected in the residue samples could be emitted through various biomass burning experiments and are not source-specific [23]. Those compounds were not detected either in the blank sample or the back side of the grinding plate (12SCM15:9), which could exclude the contamination.

Previous studies showed that the major difference between pine-soot and oil-soot is the relative abundance 


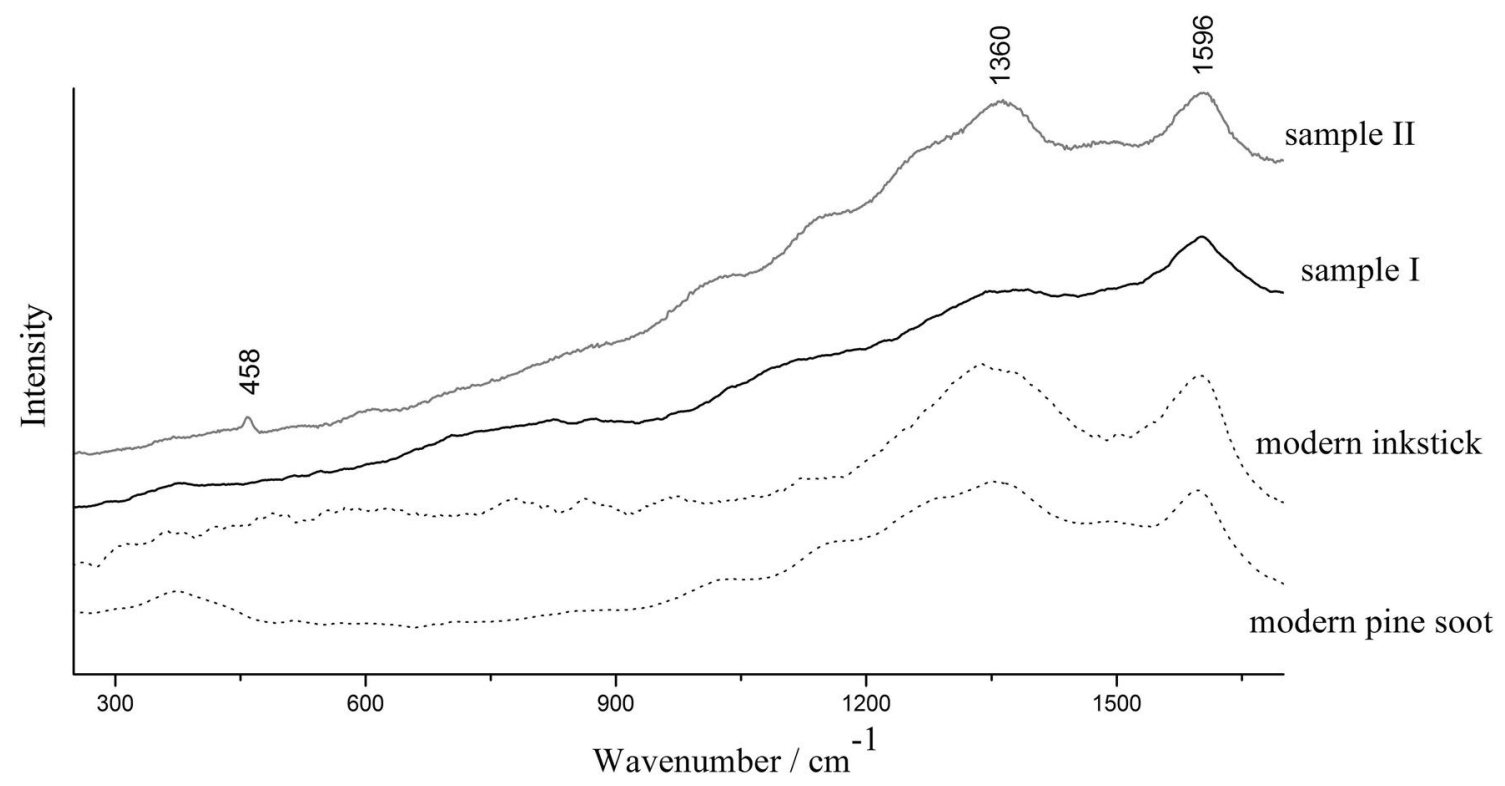

Fig. 3 Raman spectra of the archaeological residues, the modern pine soot, and the modern inkstick

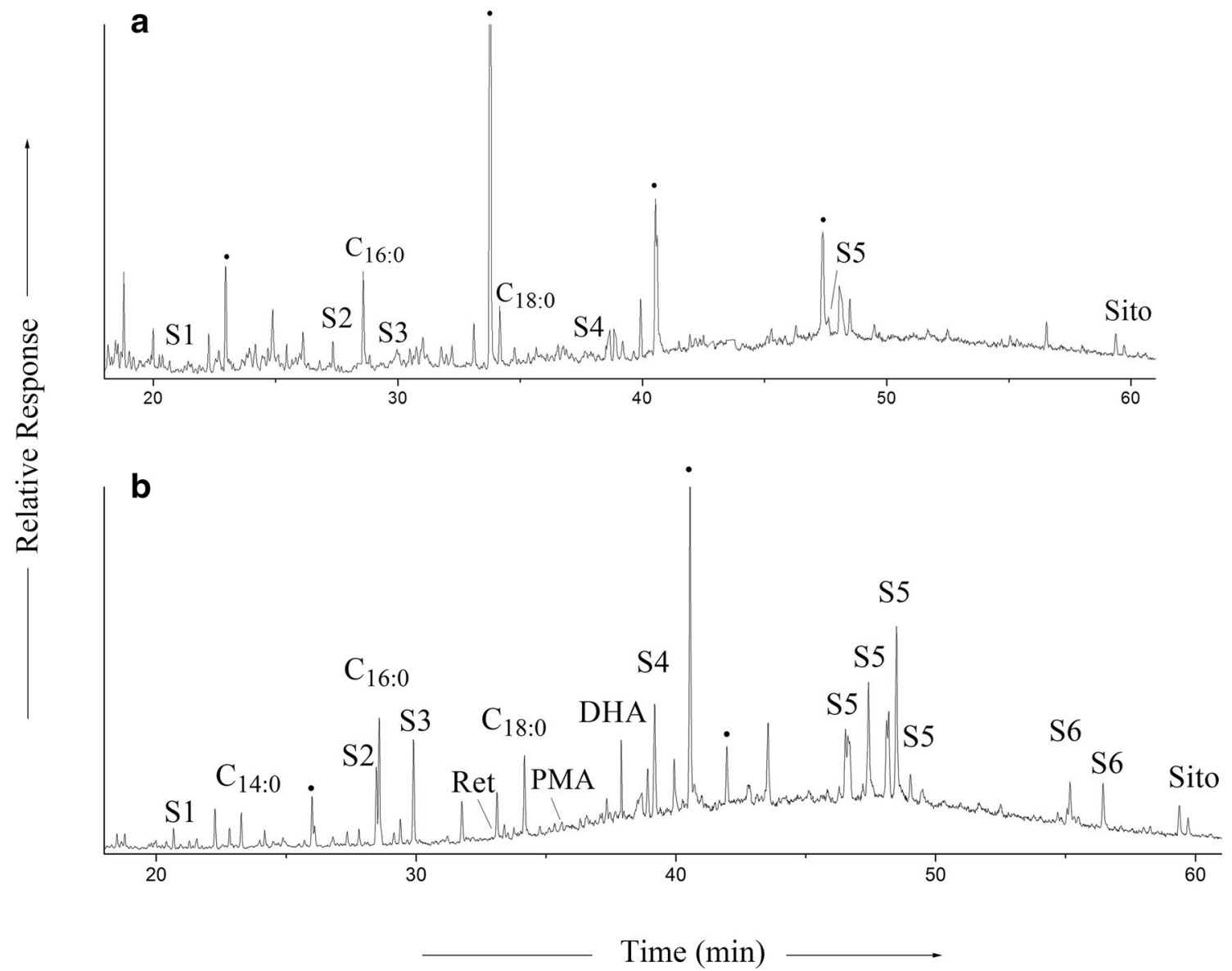

Fig. 4 Total ion current (TIC) chromatograms of sample I (a) and sample II (b). Chromatographic peak assignments are shown in Table 1; black dots refer to plasticizers absorbed by samples stored in plastic bags and other contaminants which may have been introduced during the extraction or analytical procedures in comparison with blank sample 
Table 1 Peak assignments related to the chromatograms in Fig. 4 and the description of the compounds identified in the archaeological residue samples

\begin{tabular}{|c|c|c|c|c|c|}
\hline Sample & Peak & Retention time/min & Composition & Main $\mathrm{m} / \mathrm{z}$ values $\mathrm{s}^{\mathrm{a}}$ & Compound \\
\hline \multirow[t]{8}{*}{ Sample I } & S1 & 20.67 & $\mathrm{C}_{14} \mathrm{H}_{10}$ & $76,89,152, \underline{178}$ & Phenanthrene \\
\hline & S2 & 28.45 & $\mathrm{C}_{16} \mathrm{H}_{10}$ & $101, \underline{202}$ & Fluoranthene \\
\hline & $C_{16: 0}$ & 28.58 & $\mathrm{C}_{16} \mathrm{H}_{32} \mathrm{O}_{2}$ & $73,117, \underline{31}^{b}$ & Palmitic acid \\
\hline & S3 & 29.91 & $\mathrm{C}_{16} \mathrm{H}_{10}$ & $101, \underline{202}$ & Pyrene \\
\hline & $C_{18: 0}$ & 34.17 & $\mathrm{C}_{18} \mathrm{H}_{36} \mathrm{O}_{2}$ & $73,117,{\underline{341^{b}}}^{b}$ & Stearic acid \\
\hline & S4 & 38.64 & $\mathrm{C}_{18} \mathrm{H}_{12}$ & $114, \underline{228}$ & Benz[a]anthracene \\
\hline & S5 & 47.55 & $\mathrm{C}_{20} \mathrm{H}_{12}$ & $126, \underline{252}$ & Benzo[k]fluoranthene \\
\hline & Sito & 59.36 & $\mathrm{C}_{29} \mathrm{H}_{50} \mathrm{O}$ & $73,129,357,396^{b}$ & $\beta$-Sitosterol \\
\hline \multirow[t]{18}{*}{ Sample II } & S1 & 20.67 & $\mathrm{C}_{14} \mathrm{H}_{10}$ & $76,89,152, \underline{178}$ & Phenanthrene \\
\hline & $C_{14: 0}$ & 22.81 & $\mathrm{C}_{14} \mathrm{H}_{28} \mathrm{O}_{2}$ & $73,117, \underline{285^{b}}$ & Tetradecanoic acid \\
\hline & S2 & 28.48 & $\mathrm{C}_{16} \mathrm{H}_{10}$ & $101,122, \underline{202}$ & Fluoranthene \\
\hline & $C_{16: 0}$ & 28.57 & $\mathrm{C}_{16} \mathrm{H}_{32} \mathrm{O}_{2}$ & $73,117, \underline{31}^{b}$ & Palmitic acid \\
\hline & S3 & 29.90 & $\mathrm{C}_{16} \mathrm{H}_{10}$ & $101,174, \underline{202}$ & Pyrene \\
\hline & Ret & 32.93 & $\mathrm{C}_{18} \mathrm{H}_{18}$ & $189,204, \underline{219}, 234$ & Retene \\
\hline & $C_{18: 0}$ & 34.17 & $\mathrm{C}_{18} \mathrm{H}_{36} \mathrm{O}_{2}$ & $73,117, \underline{341^{b}}$ & Stearic acid \\
\hline & PMA & 35.61 & $\mathrm{C}_{20} \mathrm{H}_{30} \mathrm{O}_{2}$ & $73, \underline{121}, 257,359^{b}$ & Pimaric acid \\
\hline & DHA & 37.88 & $\mathrm{C}_{20} \mathrm{H}_{28} \mathrm{O}_{2}$ & $73,239,357,372^{b}$ & Dehydroabietic acid \\
\hline & S4 & 38.91 & $\mathrm{C}_{18} \mathrm{H}_{12}$ & $114, \underline{228}$ & Benz[a]anthracene \\
\hline & S4 & 39.17 & $\mathrm{C}_{18} \mathrm{H}_{12}$ & $114, \underline{228}$ & Triphenylene \\
\hline & S5 & 46.52 & $\mathrm{C}_{20} \mathrm{H}_{12}$ & $126, \underline{252}$ & Benzo[a]pyrene \\
\hline & S5 & 47.54 & $\mathrm{C}_{20} \mathrm{H}_{12}$ & $126, \underline{252}$ & Benzo[k]fluoranthene \\
\hline & S5 & 48.19 & $\mathrm{C}_{20} \mathrm{H}_{12}$ & $126, \underline{252}$ & Benzo[k]fluoranthene \\
\hline & S5 & 49.03 & $\mathrm{C}_{20} \mathrm{H}_{12}$ & $126, \underline{252}$ & Benzo[b]fluoranthene \\
\hline & S6 & 55.39 & $\mathrm{C}_{22} \mathrm{H}_{12}$ & $138, \underline{276}$ & Indeno[1.2.3-cd]pyrene \\
\hline & S6 & 56.45 & $\mathrm{C}_{22} \mathrm{H}_{12}$ & $138, \underline{276}$ & Benzo[ghi]peryene \\
\hline & Sito & 59.38 & $\mathrm{C}_{29} \mathrm{H}_{50} \mathrm{O}$ & $73, \underline{129}, 357,396^{\mathrm{b}}$ & $\beta$-Sitosterol \\
\hline
\end{tabular}

a Base peak is underscored

b Analysed as trimethylsilyl derivative

of the main PAHs, especially the relative amount of S5 $(\mathrm{m} / \mathrm{z} 252)$, which is above $20 \%$ in pine-soot and less than $17 \%$ in oil-soot $[4,13]$. Accordingly, GC-MS in the selected ion mode (SIM) was also carried out to examine the relative abundances of the main PAHs in the archaeological residues. The relative percentages of the main PAHs were calculated based on the peak area, which were calculated and normalized automatically (Fig. 5 and Additional file 6: Table S1). The relative contents of S5 in sample I and sample II were $36.58 \%$ and $54.56 \%$, respectively, which are both above $20 \%$, suggesting that they were made by pinesoot rather than oil-soot. Similar results were also found in the modern samples (Additional file 6: Table S1).

For sample II, more direct evidence was found with the detection of retene, pimaric acid (PMA) and dehydroabietic acid (DHA) (Fig. 4b and Table 1). Retene is a tricyclic PAH derived from abietane diterpenics structure and was proposed as a tracer for conifer combustion [24]; dehydroabietic acid is a common oxidative breakdown product of abietane diterpenoids [25]. The diterpenoid components of abietane and pimarane skeletal types are characteristic of conifers $[25,26]$. These results further confirm the PAHs findings. However, these marker compounds were not detected in sample I and modern samples, which is probably due to different methods of making pine-soot [13].

\section{The significance of funerary inkstones}

Inkstones were widely used in daily life and often buried with their owners during the Han Dynasty as a part of the prevailing funeral ceremony. They were usually buried alongside some other practical writing implements, such as inksticks, writing brushes, sharpeners, bamboo slips, etc. Archaeological materials also show that most of the owners tend to be males and belong to the upper and middle classes of their contemporary societies [8]. In this study, an iron sharpener was also found in the tomb, and the owner was deduced as an official scribe [16]. The slight differences 


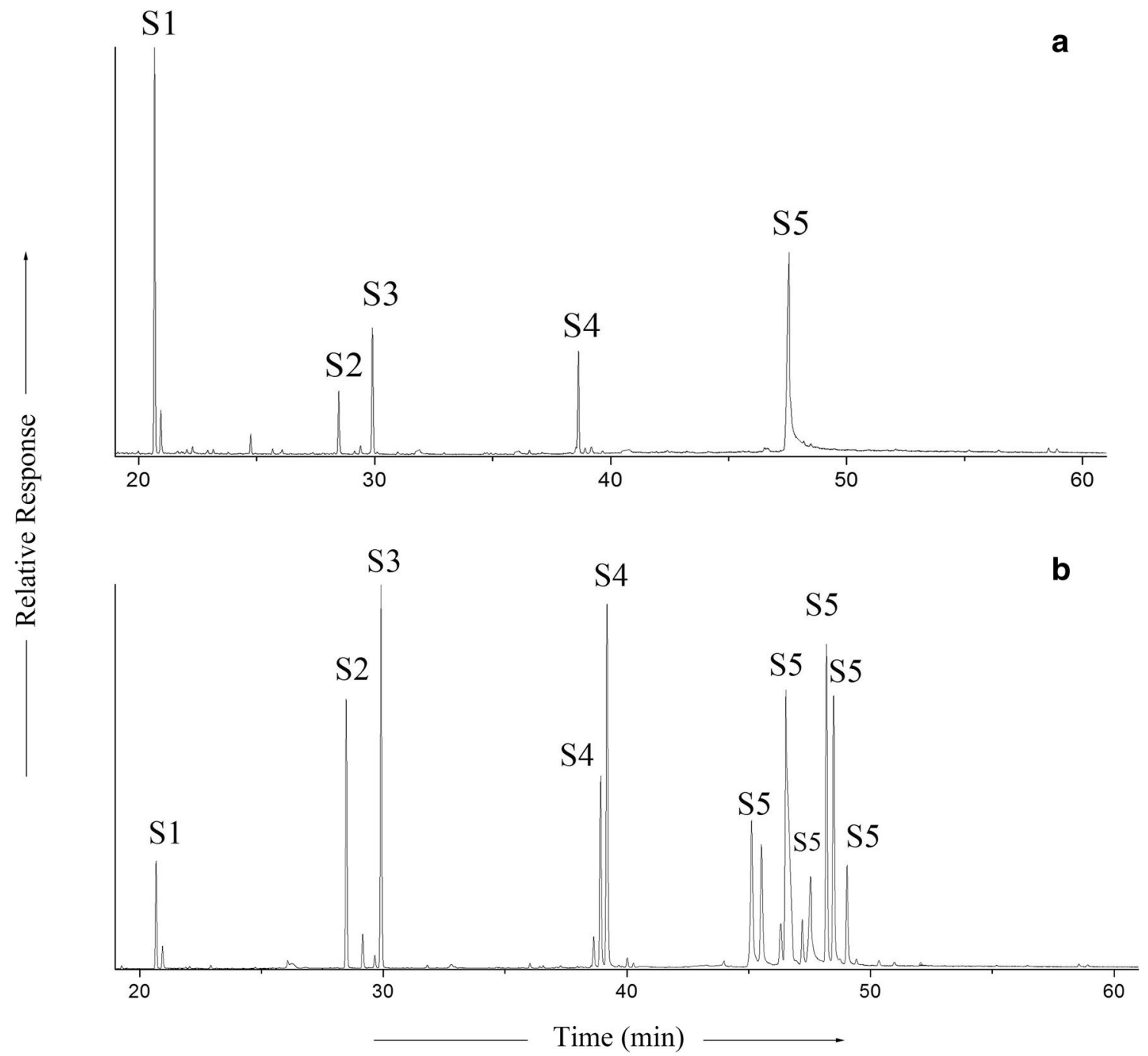

Fig. 5 The select ions chromatograms (SIM) of sample I (a) and sample II (b)

in the organic compounds between the residues on the grinding plate and the grinding stone in the present study indicated that they might not come from the same set in use. However, they were buried together as a set, which should be used to reflect the characteristic of inkstone shapes and burial custom in the Western Han Dynasty.

\section{The co-evolution between ink manufacture and inkstone shapes}

The absence of additives and binding media in the archaeological samples could be attributed to the less developed technique of ink manufacturing in the early times. Specially, very little or no binding media was added in ancient ink residues, which might explain why the inks were produced as small and irregular pellets during the Western Han Dynasty. For the ink pellets, it is necessary to use a small grinding stone to press them when grinding against a plate. With the addition of animal glue, the hardness of the inkstick would greatly increase. Such inkstick can be readily used for grinding; then, the small grinding stone would not be necessary. Since the Wei-Jin period, the mature concave inkstone, with the specific function of grinding and containing ink, became the main type of inkstone and is still used until today $[8,11]$. Animal glue was also found in one ingot-type inkstick of the Eastern Jin period (317420 AD) [13]. Taken together, these findings are likely to support the assumption that the morphological evolution of inkstones was closely related to the ingredients and manufacturing techniques of artificial inks from the Western Han Dynasty to the Wei-Jin period (Additional file 1: Figure S1). However, more research should be carried out to better understand their correlation. 


\section{Conclusions}

The black residues on a proto-inkstone unearthed in a middle-late Western Han tomb (140 BC-AD 8) in the Changle Cemetery were characterised by FTIR, Raman and GC-MS analyses. On the basis of the relative abundances of the main PHAs, as well as the detection of conifer biomarkers, the archaeological residues have been identified as pine-soot ink, and, through comparison with a modern inkstick, suggest that animal glue was not added to them. Consequently, the excavated stone artefacts were used for grinding ink. The findings reported here appear to support the assumption that the combination of the grinding plate with a small grinding stone was a form of protoinkstone during the Western Han Dynasty; and further suggest that the composition and manufacture of inksticks have a profound influence on the inkstone shapes.

Further investigations of the ink residues are strongly recommended, owing to the fact that early ink is rarely found at archaeological sites. The chemical analysis of ink traces on inkstones, bamboo slips or painted objects could help to provide reliable evidence of their compositions and production technology.

\section{Additional files}

Additional file 1: Figure S1. Chinese inkstones from different periods: $(\mathbf{a}, \mathbf{b})$ a round/rectangular stone plate with a small grinding stone in the

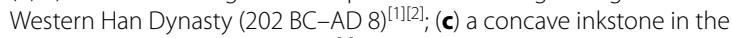
Wei-Jin Dynasties (AD 220-420) ${ }^{[3]}$; (d) an inkstone in the contemporary age (collected in National Museum of China).

[1] HPICR (Hubei Provincial Institute of Cultural Relics) (1993) Fenghuangshan M168 of the Han Dynasty in Jiangling County (in Chinese), Acta Archaeologica Sinica, 4: 455-513.

[2] Yun J (2015) Inkstones (in Chinese). Hangzhou City. Zhejiang Ancient Book Publishing House.

[3] IA CASS (Institute of Archaeology, Chinese Academy of Social Sciences), MAT (Museum of Ancient Tombs in Luoyang) (1994) Excavation of Jing tomb of Xuanwu Emperor in the Northern Wei Dynasty (in Chinese), Archaeology, 9, 801-814.

Additional file 2: Figure S2. The extraction solvent of chloroform/ methanol (2:1 V/V) (a) and acetone (b) after centrifugation.

Additional file 3: Figure S3. Total ion current (TIC) chromatograms of the modern pine soot samples with different sampling methods: (a) TIC chromatogram of PS 1, (b) TIC chromatogram of PS 2. Chromatographic peak assignments are shown in Additional file 6: Table S1.

Additional file 4: Figure S4. The select ions chromatograms (SIM) of PS 1 (a) and PS 2 (b).

Additional file 5: Figure S5. TIC chromatogram of the modern pinesoot inkstick.

Additional file 6: Table S1. The relative abundance of main PAHs in the archaeological residues and modern pine soot samples by GC-SIM-MS analysis.

\section{Abbreviations}

FTIR-ATR: Fourier transform infrared spectroscopy-attenuated total reflection; GC-MS: gas chromatography-mass spectroscopy; PAHs: polycyclic aromatic hydrocarbons; S1: phenanthrene; S2: fluoranthene; S3: pyrene; S4: benz[a] anthracene, triphenylene; 55 : benzo[a]pyrene, benzo[k]fluoranthene, benzo[b] fluoranthene; S6: indeno[1, 2, 3-cd] pyrene; TIC: total ion current; SIM: select ion mode; PMA: pimaric acid; DHA: dehydroabietic acid.

\section{Authors' contributions}

YMY developed the concept of this work. RFW provided the archaeological samples and archaeological background. MR contributed to acquisition and analysis of the data. MR and YMY contributed to data interpretation and all authors helped drafting and revising the manuscript. All authors read and approved the final manuscript.

\section{Author details}

${ }^{1}$ Key Laboratory of Vertebrate Evolution and Human Origins of Chinese Academy of Sciences, Institute of Vertebrate Paleontology and Paleoanthropology, Chinese Academy of Sciences, Beijing 100044, People's Republic of China.

${ }^{2}$ Department of Archaeology and Anthropology, University of Chinese Academy of Sciences, Beijing 100049, People's Republic of China. ${ }^{3}$ NingXia Institute of Cultural Relics and Archaeology, Yinchuan 750001, People's Republic of China.

\section{Competing interests}

The authors declare that they have no competing interests.

\section{Ethics approval and consent to participate}

Not applicable.

\section{Funding}

This study was supported by the grants from the CAS Strategic Priority Research Program (XDA05130303) and Youth Innovation Promotion Association of CAS.

\section{Publisher's Note}

Springer Nature remains neutral with regard to jurisdictional claims in published maps and institutional affiliations.

Received: 22 December 2017 Accepted: 14 March 2018

Published online: 23 March 2018

\section{References}

1. Chen TY. Chinese calligraphy. Beijing: China Intercontinental Press; 2003.

2. IACAS (Institute of Archaeology of Chinese Academy of Sciences), Banpo Museum, The Neolithic village at Panpo. Beijing: Cultural Relics Press; 1963 (in Chinese).

3. CGSHD (Compile Group of Qin Tombs in Shuihudi) Qin (Chin) Tombs in Shuihudi, Yunmeg County. Beijing: Cultural Relics Press; 1981 (in Chinese).

4. Wei SY, Fang XY, Cao XJ, Schreiner M. Characterization of the materials used in Chinese ink sticks by pyrolysis-gas chromatography-mass spectrometry. J Anal Appl Pyrolysis. 2011;91(1):147-53.

5. Wang W. Researches on traditional Chinese techniques of inkstick production. Hefei: University of Science and Technology of China; 2010 (in Chinese).

6. Sun J. Illustrated explanations of the material culture of the Han Dynasty. Beijing: Cultural Relic Press; 1991 (in Chinese).

7. Ye Q. Illustration of the inkstone history. Cult Relic. 1964;1:49-52 (in Chinese).

8. Liu YZ. Research on inkstones excavated in Han Dynasty. Zhengzhou: Zhengzhou University; 2011 (in Chinese).

9. Gao MH. Grinding stone and inkstone in the Han Dynasty. China Cult Relics News. 2010;8:6 (in Chinese).

10. Wang HT, Cui JJ. The excavation of Warring States and Western Han tombs in Xujia Village, Shandong Province, China. Archaeology. 2006;1:19-29 (in Chinese)

11. Shen XX, Zhang JZ, Fang XY. From grinding stone to present Inkstone: on the preliminary development of Inkstone's Shape. Southeast Cult. 2011:3:65-8 (in Chinese).

12. Swider JR, Hackley VA, Winter J. Characterization of Chinese ink in size and surface. J Cult Heritage. 2003;4(3):175-86. 
13. Wei SY, Fang XY, Cao XJ, Pintus V, Schreiner M, Song GD. Identification of the materials used in an Eastern Jin Chinese ink stick. J Cult Heritage. 2012;13(4):448-52.

14. Nir-El Y, Broshi M. The black ink of the Qumran Scrolls. Dead Sea Discov. 1996:3(2):157-67.

15. Canevali C, Gentile P, Orlandi M, Modugno F, Lucejko JJ, Colombini MP, Brambilla L, Goidanich S, Riedo C, Chiantore O, Baraldi P, Baraldi C, Gamberini MC. A multi-analytical approach for the characterization of powders from the Pompeii archaeological site. Anal Bioanal Chem. 2011;401(6):1801-14.

16. Wang RF, Chen XH. 2012 year archaeological excavation of Han period tombs at Changle in Zhongwei, Ningxia. Major archaeological discoveries in China in 2012. Beijing: Cultural Relic Press; 2013 (in Chinese)

17. Oudemans TFM, Boon JJ, Botto RE. FTIR and solid-state 13C CP/MAS NMR spectroscopy of charred and non-charred solid organic residues preserved in Roman Iron Age vessels from the Netherlands. Archaeometry. 2007:49(3):571-94.

18. Solomon D, Lehmann J, Kinyangi J, Liang B, Schafer T. Carbon K-edge NEXAFS and FTIR-ATR spectroscopic investigation of organic carbon speciation in soils. Soil Sci Soc Am J. 2005;69(1):107-19.

19. Devièse T, Ribechini E, Castex D, Stuart B, Regert M, Colombini MP. A multi-analytical approach using FTIR, GC/MS and Py-GC/MS revealed early evidence of embalming practices in Roman catacombs. Microchem J. 2017;133:49-59.

20. Derrick MR, Stulik D, Landry JM. Infrared spectroscopy in conservation science. Los Angeles: Getty Publications; 1999.

21. Smith GD, Clark RJ. Raman microscopy in archaeological science. J Archaeol Sci. 2004;31(8):1137-60.

22. Bell IM, Clark RJH, Gibbs PJ. Raman spectroscopic library of natural and synthetic pigments (pre- 1850 AD). Spectrochim Acta Part A Mol Biomol Spectrosc. 1997;53(12):2159-79.

23. Simoneit BR. Biomass burning - a review of organic tracers for smoke from incomplete combustion. Appl Geochem. 2002;17(3):129-62.

24. Ramdahl T. Retene-a molecular marker of wood combustion in ambient air. Nature. 1983;306:580-2.

25. Stacey RJ, Cartwright CR, McEWAN C. Chemical characterization of ancient Mesoamerican 'copal' resins: preliminary results. Archaeometry. 2006;48(2):323-40

26. Reber EA, Hart JP. Pine resins and pottery sealing: analysis of absorbed and visible pottery residues from central New York State. Archaeometry. 2008;50(6):999-1017.

\section{Submit your manuscript to a SpringerOpen ${ }^{\odot}$ journal and benefit from:}

- Convenient online submission

- Rigorous peer review

- Open access: articles freely available online

- High visibility within the field

- Retaining the copyright to your article

Submit your next manuscript at springeropen.com 